\title{
Metal and Organic Templates Together Control the Size of Covalent Macrocycles and Cages
}

\author{
Roy Lavendomme, Tanya K. Ronson, Jonathan R. Nitschke* \\ Department of Chemistry, University of Cambridge, Lensfield Road, Cambridge CB2 1EW, United Kingdom.
}

\begin{abstract}
Covalent macrocycles and three-dimensional cages were prepared by the self-assembly of di- or tri-topic anilines and 2,6-diformylpyridine subcomponents around palladium(II) templates. The resulting 2,6-bis(imino)pyridyl-Pd ${ }^{\mathrm{II}}$ motif contains a tridentate ligand leaving a free coordination site on the $\mathrm{Pd}^{\mathrm{II}}$ centers, which points inward. The binding of ligands to the free coordination sites in these assemblies was found to alter the product stability, and multi-topic ligands could be used to control product size. Multi-topic ligands also bridged metallomacrocycles to form higher-order supramolecular assemblies, which were characterized via NMR spectroscopy, mass spectrometry and X-ray crystallography. An efficient method was developed to reduce the imine bonds to secondary amines, leading to fully organic covalent macrocycles and cages, which were inaccessible through other means.
\end{abstract}

\section{Introduction}

Covalent organic macrocycles ${ }^{1}$ and cages $^{2}$ have found wide application. These structures serve as hosts for guest recognition, ${ }^{3}$ in molecular separations, ${ }^{4}$ as catalysts, ${ }^{5}$ for surface modification, ${ }^{6}$ and enable the generation of new mechanically interlocked molecular architectures. ${ }^{7}$ The preparation of these species is not trivial, however, as many covalent bonds need to be formed in the correct geometry to enable macrocycles and cage structures to come together. Where bonds are not formed reversibly, the formation of off-pathway kinetic products can limit the yield of a desired species, rendering product isolation challenging. Higher yields and cleaner products may be obtained through the use of templates ${ }^{8}$ and reversibly-formed linkages $^{9}$ such as imines, ${ }^{10}$ boronic esters ${ }^{11}$ and alkenes ${ }^{12}$ or alkynes $^{13}$ (with appropriate catalysts). The use of such dynamic-covalent bonds leads to the formation of thermodynamic products, but such products may show limited stability due to cleavage of the dynamic bonds, such as hydrolysis of imines.

Functional macrocycles and cages can also be prepared using metal-organic self-assembly. ${ }^{14}$ Palladium(II) is among the most frequently employed metals for metal-organic assemblies. ${ }^{15} \mathrm{Pd}^{\mathrm{II}}$-based assemblies often incorporate two or four pyridine-based ligands coordinated to each palladium center. These assemblies benefit from the strong propensity of palladium(II) to adopt a square planar coordination geometry, ${ }^{16}$ allowing the $90^{\circ}$ angles between ligands to translate into structural elements within larger assemblies, from two-dimensional macrocycles to three-dimensional cages. ${ }^{15 a}$ The use of $\mathrm{Pd}^{\mathrm{II}}$ in subcomponent selfassembly, where intricate metal complexes are brought together at the same time as the multi-topic ligands that compose them are templated, has provided access to small macrocycles, (pseudo-)rotaxanes and a catenane ${ }^{17}$ Here we report the use of this technique to generate a new class of macrocycles, as well as cages and larger assemblies. These macrocycles and cages were demetallated and reduced, yielding large, complex organic structures whose preparation would be otherwise difficult to envisage.

\section{Results and Discussion}

Properties of the bis(imino)pyridyl-Pd II building block. In order to elucidate the design principles for this class of Pd-templated architectures, we carried out a careful analysis of the crystal structures of complexes bearing a 2,6-bis(imino)pyridyl-Pd ${ }^{\text {II }}$ moiety. ${ }^{17}$ The angle between the aniline residues ranged from $87^{\circ}$ to $97^{\circ}$ (see Figures 1 and S83). ${ }^{18}$ This motif may thus be used to engender an angle close to $90^{\circ}$ but displaying some flexibility. Moreover, the tridentate ligand leaves one free coordination site on $\mathrm{Pd}^{\mathrm{II}}$ that can bind a chosen monodentate ligand. Nabeshima et al. recently used such free coordination sites within $\mathrm{Pd}^{\text {II }}$ complexes to control their conformation..$^{19}$ Notably, the condensation of anilines and 2,6-diformylpyridine 1 with no metal template would result in an angle between aniline residues close to $120^{\circ}$ and prone to torsion about the $\mathrm{NCH}$ pyridyl bonds. These additional degrees of freedom could lead to the formation of mixtures of structures, as opposed to the single products observed in our study.

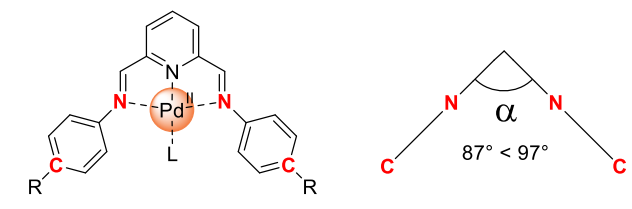

Figure 1. The 2,6-bis(imino)pyridyl-Pd ${ }^{\mathrm{II}}$ motif provides a $90^{\circ}$ bend within higher-order structures. 


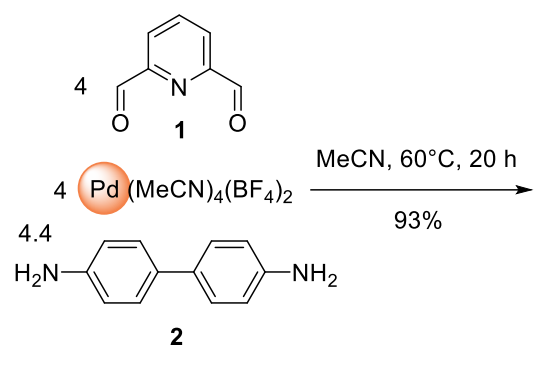

2
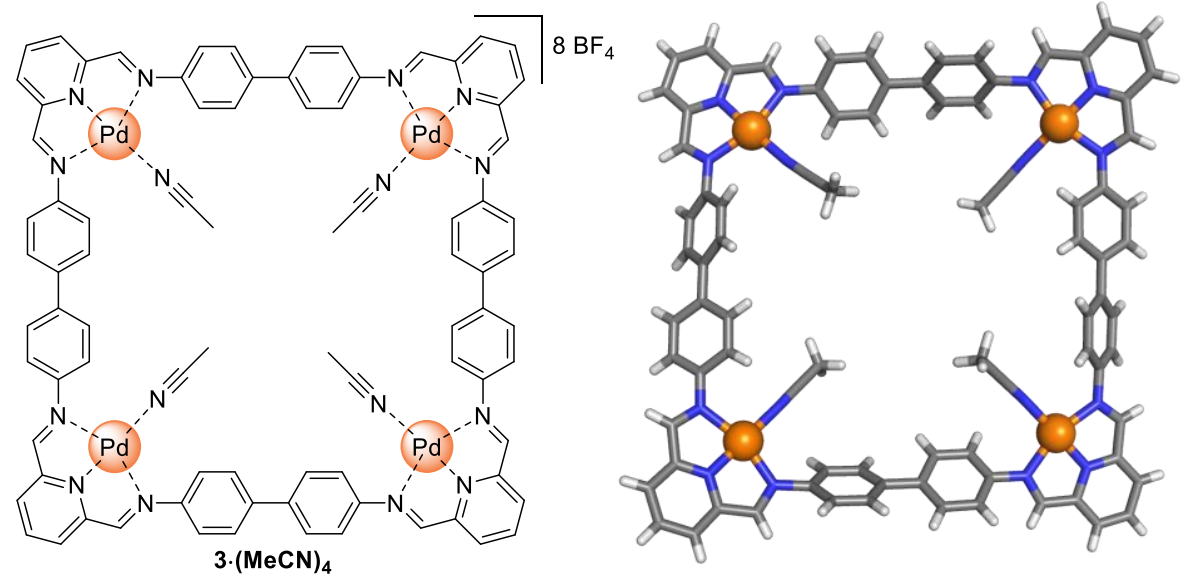

a Anions and free solvent molecules are not shown for clarity.

Covalent Macrocycles. The reaction of 2,6-diformylpyridine $\mathbf{1}$, benzidine 2 , and $\left[\mathrm{Pd}(\mathrm{MeCN})_{4}\right]\left(\mathrm{BF}_{4}\right)_{2}$ in a $1: 1.1: 1$ ratio in acetonitrile afforded clean formation of $\mathrm{Pd}_{4}{ }_{4}[4+4]$ square complex 3.(MeCN)$)_{4}$ (Scheme 1). If a slight excess of 2 was not employed, traces of a secondary species were observed by ${ }^{1} \mathrm{H}$ NMR spectroscopy. We infer that the excess 2 led to the disappearance of the secondary species, possibly as a consequence of dynamic imine exchange being catalyzed by the additional aniline present.

Crystals of 3 were grown by slow diffusion of diisopropyl ether $\left(i \mathrm{Pr}_{2} \mathrm{O}\right)$ into an $\mathrm{MeCN}$ solution in the presence of $\mathrm{KAsF}_{6}(20$ equiv/Pd). Single crystal X-ray diffraction revealed the structure of complex 3 (Scheme 1). Solid 3 adopts a conformation having angles between the phenylene rings at each corner of $\alpha=89^{\circ}$ and $95^{\circ}$.

Square complex 3 evokes the [(ethylenediamine) $\left.\mathrm{Pd}^{\mathrm{II}}\right]_{4}(4,4 \text { '-bipyridine })_{4}$ structure originally reported by Fujita and co-workers ${ }^{20}$ and related square coordination macrocycles including various linear divalent ligands later reported by Stang and co-workers. ${ }^{21}$ Differences between this key Fujita precedent and 3, and by extension the other structures reported herein, include: (i) a longer distance between adjacent Pd ${ }^{\mathrm{II}}$ centers in 3 (12.3 $\AA$ ) than in the Fujita square (11.1 $\AA$ ); (ii) a fully covalent skeleton in 3; (iii) trans coordination of imines around $\mathrm{Pd}^{\mathrm{II}}$ in $3 \cdot(\mathrm{MeCN})_{4} v s$. cis coordination of pyridines in the Fujita structure; and (iv) a free coordination site for additional ligands pointing inside the macrocycle for 3 , as opposed to two outwardfacing coordination sites, necessarily occupied by bidentate ligands, in the relevant Fujita precedents.

The successful ESI-MS analysis of square 3 required the replacement of its acetonitrile ligands with 2,6-bis(trimethylsilylalkynyl)pyridines (Figures S6 and S7). We infer that these stronger and more hindered mono-dentate ligands stabilized the $\mathrm{Pd}_{4}{ }_{4}$ skeleton of 3, disfavoring monodentate ligand loss and the rearrangement reactions that follow under ESI-MS analysis conditions.

The more flexible 4,4'-oxydianiline $\mathbf{4}$ had been reported to self-assemble with 1 and $\left[\mathrm{Pd}(\mathrm{MeCN})_{4}\right]\left(\mathrm{BF}_{4}\right)_{2}$ to form the $\mathrm{Pd}_{3}[3+3]$ macrocycle 5.(MeCN$)_{3}$ which was isolated by size-exclusion chromatography (Scheme 2) ${ }^{17}$ The addition of the $n \mathrm{Bu}_{4} \mathrm{~N}^{+}$salts of $\mathrm{Cl}^{-}, \mathrm{Br}^{-}, \mathrm{I}^{-}$, or $\mathrm{SCN}^{-}$resulted in the displacement of the acetonitrile ligands of $\mathbf{5}$ by these anions (Figure S69). In contrast, the addition of fluoride led to degradation. The products $\mathbf{5} \cdot \mathbf{C l}_{3}$ and $\mathbf{5} \cdot \mathbf{B r} \mathbf{r}_{3}$ were stable in solution and under ESI-MS conditions (Figures S70 and S7l), whereas $\mathbf{5} \cdot \mathbf{I}_{3}$ and $\mathbf{5} \cdot(\mathbf{S C N})_{3}$ degraded in acetonitrile over 2 days at room temperature.

As-synthesized 5-( $\mathrm{MeCN})_{3}$ showed a minor set of peaks in the ${ }^{1} \mathrm{H}$ NMR spectrum (Figure S69). We inferred these peaks to correspond to the $\mathrm{Pd}_{4}{ }_{4}[4+4]$ macrocycle 6. $(\mathrm{MeCN})_{4}$ (Scheme 2$)$. In order to obtain these macrocycles directly in a pure state, we employed the inward-facing coordination sites on the palladium centers to selectively form either the $[3+3]$ or $[4+4]$ macrocycles by using appropriate central templates. PM6-optimized models ${ }^{22,23}$ indicated that tris-pyridyl and tetrakis-pyridyl templates T1 and $\mathbf{T} 2$ would be a good size match for the macrocycles (Tables S2-S7).

The addition of tris(pyridyl) template $\mathbf{T l}$ (0.33 equiv./Pd) to the initially-formed $c a$. 4:1 mixture of $5 \cdot(\mathrm{MeCN})_{3}$ and 6. $(\mathrm{MeCN})_{4}$ afforded trimeric 5.T1 as the major species, in near-completion by NMR within 5 min at $25^{\circ} \mathrm{C}$. Further heating of the mixture to $60^{\circ} \mathrm{C}$ resulted in the disappearance of all traces of tetrameric $\mathbf{6}$ in the NMR spectrum. In contrast, the addition of tetrakis(pyridyl) template $\mathbf{T} 2$ to the initial mixture of 5.(MeCN $)_{3}$ and 6.(MeCN $)_{4}$ required heating prior to the formation of 6.T2 which ended up as the exclusively-observed product after $2 \mathrm{~h}$ at $60^{\circ} \mathrm{C}$. This difference in initial reaction speed can be explained by the fast replacement of acetonitrile by $\mathrm{Tl}$ inside $5 \cdot(\mathrm{MeCN})_{3}$, followed by the conversion of the minor tetrameric macrocycle 6 to 5 upon heating while addition of T2 requires the slow conversion of the major trimeric macrocycle 5 to tetrameric 6.T2.

Surprisingly, mixing and heating $\mathbf{1}, \mathbf{4}$, and $\mathrm{Pd}^{\mathrm{II}}$ with $\mathrm{Tl}$ in the proportions required to generate 5.T1 led to a complex mixture containing only ca. $20 \%$ of the templated macrocycle. This outcome illustrated the importance of the order of addition for the subcomponents in this case. In contrast, 
the addition of template $\mathbf{T} 2$ either before or after the formation of macrocycles 5.( $\mathrm{MeCN})_{3}$ and $\mathbf{6} \cdot(\mathrm{MeCN})_{4}$ resulted in the exclusive formation of $\mathbf{6} \cdot \mathbf{T} 2$ after heating.

Control experiments elucidated the different behavior of the two templates towards $\mathrm{Pd}^{\mathrm{II}}$. When $\mathbf{T 1}$ or $\mathbf{T} 2$ was mixed with $\left[\mathrm{Pd}(\mathrm{MeCN})_{4}\right]\left(\mathrm{BF}_{4}\right)_{2}(0.75$ or 1.0 equiv, respectively) in acetonitrile at $60{ }^{\circ} \mathrm{C}$, no discrete species were observed by ${ }^{1} \mathrm{H}$ NMR. Whereas T2 afforded a strongly colored solution, Tl gave a precipitate and colorless solution, suggesting the removal of soluble $\mathrm{Pd}^{\mathrm{II}}$ species, which are usually colored. We thus infer that the one-step formation of 5.T1 is prevented by the initial precipitation of a Pd ${ }^{\mathrm{II}}$-Tl adduct. We note that $\mathbf{T} 2$ has already been reported to form heteroleptic complexes with $\mathrm{Pd}^{\mathrm{II}}{ }^{24}$ but that 5.T1 is the first report of a Pd ${ }^{\mathrm{II}}$ complex involving $\mathrm{Tl}$ as a ligand.
The ${ }^{1} \mathrm{H}$ NMR spectra of 5.T1 and 6.T2 showed several sets of signals (Figures S9 and 2), which were attributed to different conformers having distinct orientations of the pyridyl moieties of the templates (i.e. either above or below the plane of the PdII centers). DOSY analyses revealed the different sets of signals to correspond to species of similar sizes (Figures S14 and S22). The ${ }^{1} \mathrm{H}$ NMR spectrum of the major species observed for 5.T1 is consistent with $C_{\mathrm{s}}$ symmetry, which is expected from the conformer presenting one inverted pyridyl moiety, i.e. a partial cone; ${ }^{25}$ only traces of other conformers are observed.

\section{Scheme 2. Selective templated assembly, reduction and demetallation of macrocycles 5 and 6.}

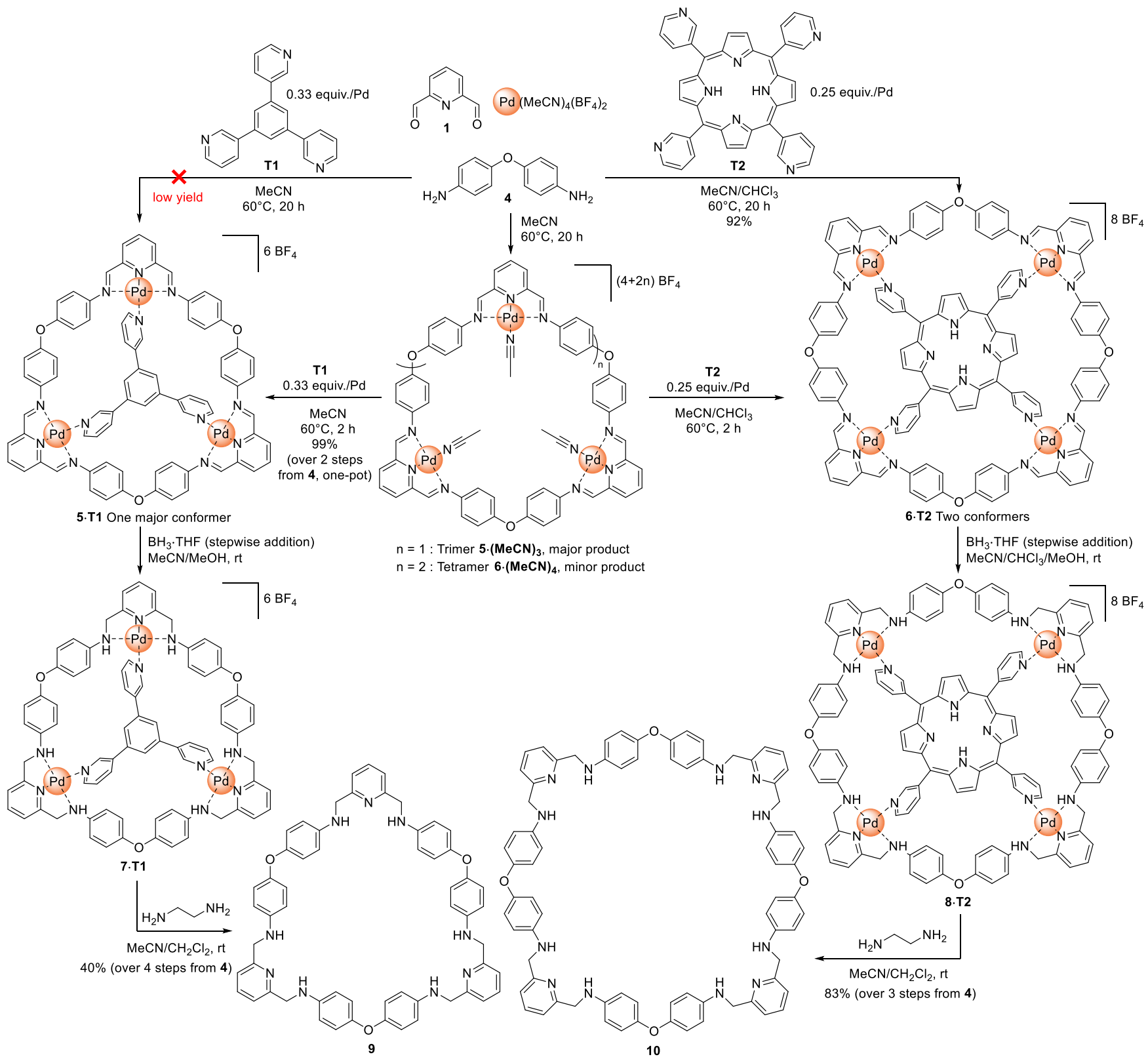


Two conformers were observed for 6.T2 (Figures 2 and S16): a $C_{\mathrm{s}}$-symmetric (partial cone ${ }^{25}$ ) conformer with a single inverted pyridyl unit, and a $C_{2 \mathrm{~h}}$ symmetric (1,2-alternate ${ }^{25}$ ) conformer with two adjacent pyridyl units inverted. The conformers of 6.T2 were observed in a $C_{\mathrm{s}} / C_{2 \mathrm{~h}}$ ratio of ca. 3:2 in $\mathrm{CD}_{3} \mathrm{CN}$ at $25^{\circ} \mathrm{C}$. EXSY NMR experiments did not show exchange between the conformers and variable temperature (VT) ${ }^{1} \mathrm{H}$ spectra showed only slight broadening of the peaks at $75{ }^{\circ} \mathrm{C}$ (Figure S23), which indicates that conformational exchange occurs slowly on the NMR chemical shift time scale. We infer the slow conformer exchange to be a consequence of the necessity of breaking a coordinative bond between the template pyridyl and $\mathrm{Pd}^{\mathrm{II}}$.

PM6 models ${ }^{22,23}$ of the four possible conformers suggested that the remaining cone and 1,3-alternate conformers $^{25}$ would lead to high-energy distortion, clarifying why they were not observed (Tables S4-S7). The presence of the pyridyl-based templates increased the stability of complexes 5.T1 and 6.T2 under ESI-MS conditions compared to their acetonitrile-bound counterparts, thus allowing their characterization by mass spectrometry (Figures S15 and S24).

Reduction and demetallation of $\mathrm{Pd}^{\mathrm{II}}$-templated macrocycles. Large covalent macrocycles are challenging to produce in high yields, often requiring high-dilution conditions. ${ }^{26}$ We thus explored the reduction and demetallation of 5.T1 and 6.T2 to produce organic macrocycles of 48 or 64 atoms in circumference.
Reducing conditions were screened for non-templated macrocycles 5.(MeCN $)_{3}$ and 6.( $\left.\mathrm{MeCN}\right)_{4}$ and showed that the reducing agent $\mathrm{BH}_{3}$.THF in acetonitrile at room temperature gave higher yields of the secondary-amine products than did $\mathrm{NaBH}_{4}, \mathrm{LiAlH}_{4}$, or $\mathrm{NaH}$. Three changes to our initial experimental procedure were found to further optimize the yield of the reduced macrocycles. First, the $\mathrm{BH}_{3}$. THF was added in equal portions stepwise $(0.25$ equiv/imine) every $10 \mathrm{~min}$, instead of all at once. Second, reduction was carried out in the presence of methanol as a cosolvent $(\mathrm{MeCN} / \mathrm{MeOH}, 5: 1, \mathrm{v} / \mathrm{v})$ to quench excess $\mathrm{BH}_{3}$ after each addition, to avoid side reactions. Third, a strongerfield monodentate ligand than acetonitrile, such as a pyridine or chloride, served to protect the $\mathrm{Pd}^{\mathrm{II}}$ center from reduction. These optimized conditions were found to minimize the side reactions that produced undesired reduced products, such as palladium black and ring-opened macrocycles.

These optimized conditions on the mixture of $\mathbf{5} \cdot \mathbf{C l}_{3}$ and 6. $\mathrm{Cl}_{4}$ afforded a mixture of purely organic covalent macrocycles 9 and 10, which proved inseparable by chromatography. Pure 5.T1 and 6.T2, prepared as described above, however, were readily reduced and subsequently demetalated.

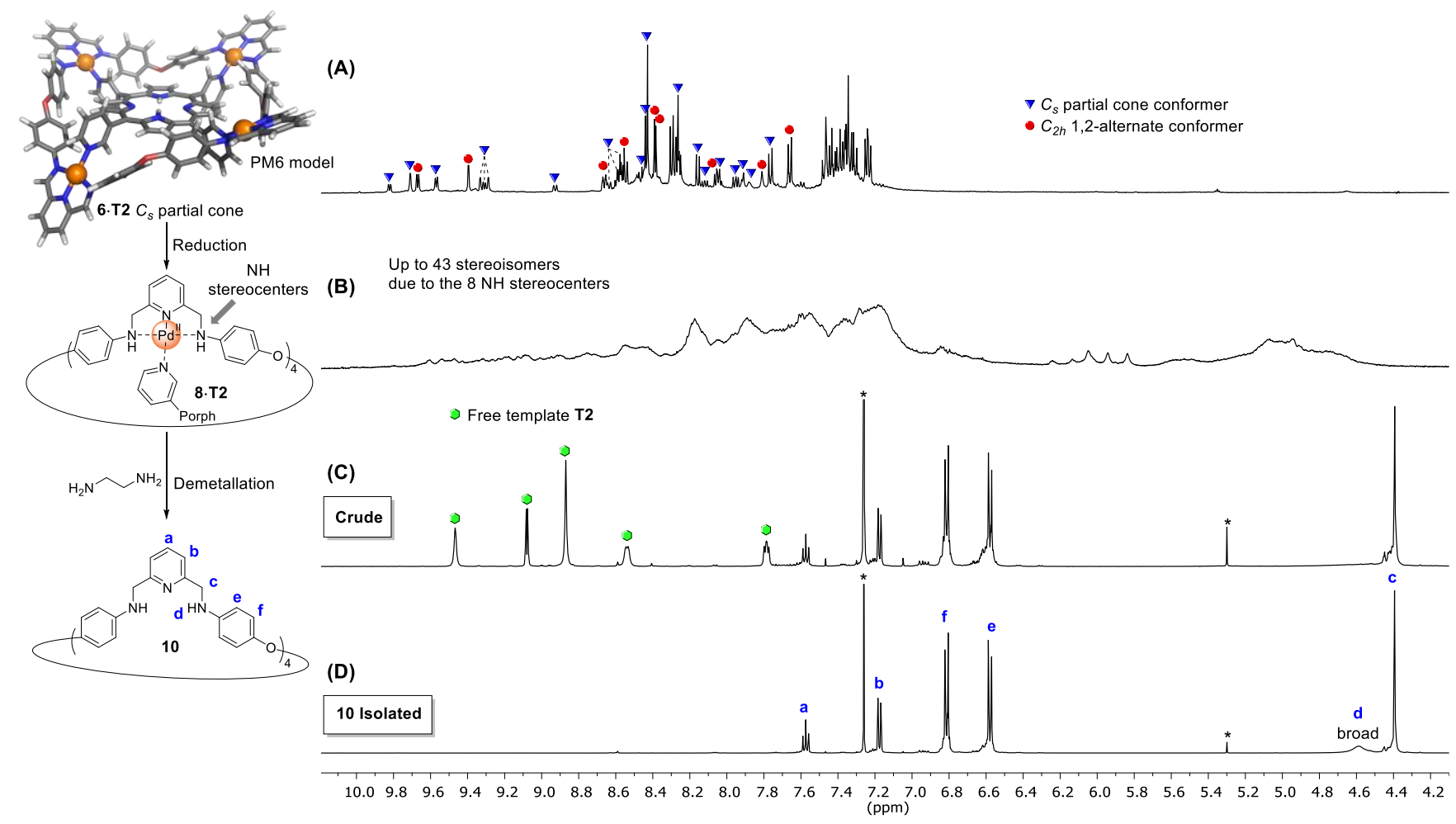

Figure 2. Top left: PM6 model of 6.T2-partial-cone. Right: ${ }^{1} \mathrm{H}$ NMR spectra $\left(500 \mathrm{MHz}, 25^{\circ} \mathrm{C}\right)$ of $(\mathrm{A})$ 6.T2 in $\mathrm{CD}{ }_{3} \mathrm{CN},(\mathrm{B}) \mathbf{8} \cdot \mathrm{T} 2$ in $\mathrm{CD}_{3} \mathrm{CN}$ (vertical scaling $\times 5$ ), (C) 10 in $\mathrm{CDCl}_{3}$ (crude material after demetallation), and (D) isolated 10 in $\mathrm{CDCl}_{3}$. ${ }^{*}$ residual solvent peaks. 
Scheme 3. Synthesis and crystal structure ${ }^{\mathrm{a}}$ of the bridged [3+3] macrocycles $5_{2} \cdot \mathrm{T}_{3}$.
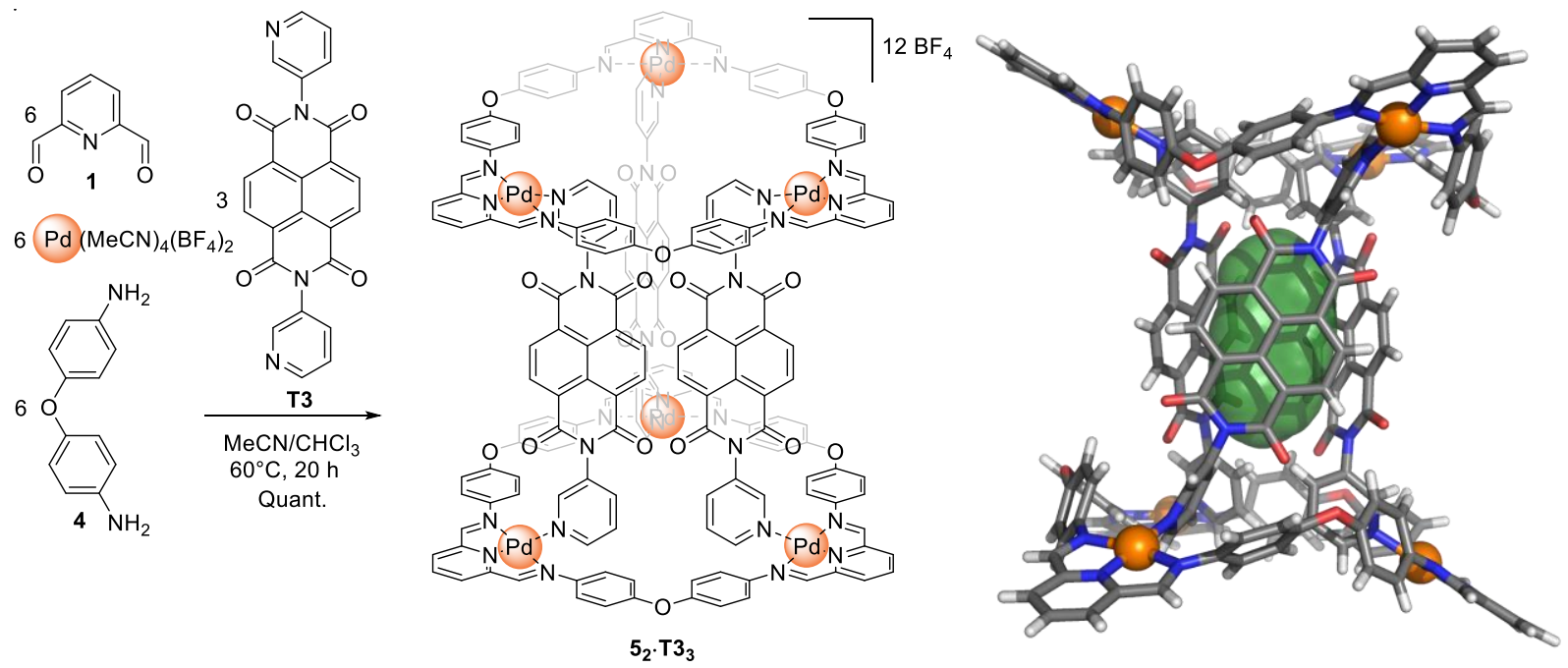

a Anions and free solvent molecules are not shown for clarity; only the right-handed helix is shown but both enantiomers are present in the crystal. The cavity of $98 \AA^{3}$ is shown in green.

Reduced macrocycles 7.T1 and 8.T2 (Scheme 2) could withstand higher cone voltage and temperatures under ESI-MS conditions than the parent imine-based macrocycles 5.T1 and 6.T2. We infer that this greater stability in the absence of imine functionality results from the impossibility of hydrolysis of the reduced macrocycles under ESI-MS conditions. We note that the ESI-MS spectra of 7.T1 and 8.T2 were consistent with a +2 oxidation state for all $\mathrm{Pd}$ centers despite the reducing conditions; as was observed for all metal-organic complexes reported herein (see SI). Compounds 7.T1 and 8.T2 displayed complex ${ }^{1} \mathrm{H}$ NMR spectra, which we infer to be a result of the large number of stereoisomers originating from the new $\mathrm{NH}$ stereocenters coordinated to the $\mathrm{Pd}^{\mathrm{II}}$ cations (see Figures S25, S26, $2 \mathrm{~B}$ and S30). Thus, we could not assess product purity at this stage and proceeded with the demetallation of 7.T1 and 8.T2 after their precipitation by addition of $\mathrm{Et}_{2} \mathrm{O}$ to $\mathrm{MeCN}$ solutions.

The demetallated trimeric (9) and tetrameric (10) macrocycles were obtained by treating $\mathbf{7 \cdot T 1}$ and $\mathbf{8 \cdot T 2}$, respectively, with ethylenediamine ( 2 equiv/Pd) as a competing ligand (Scheme 2). ${ }^{1} \mathrm{H}$ NMR analysis of the crude products showed the desired species $\mathbf{9}$ or $\mathbf{1 0}$ with the corresponding free templates $\mathbf{T 1}$ or $\mathbf{T} 2$ and traces of side products (Figures S38 and 2C). Separation of the final products from the templates and side products was achieved by preparative layer chromatography to isolate either 9 ( $40 \%$ yield) or 10 ( $83 \%$ yield). The isolated yield of $\mathbf{1 0}$ corresponds to a yield of at least $98 \%$ per imine reduction from $\mathbf{6 . T 2}$ to $8 . T 2$ if the other steps proceeded quantitatively. The isolated yield of 9 is lower despite the $c a .68 \%$ yield in the ${ }^{1} \mathrm{H}$ NMR analysis of the crude product (Figure S38) because lengthy purification was necessary to remove traces of impurities with similar polarity and solubility to the desired product 9 . The purification process allowed for the clean recovery of the free templates $\mathbf{T 1}$ and $\mathbf{T} 2$ for future use. When the one-pot syntheses of $\mathbf{9}$ or $\mathbf{1 0}$ starting from $\mathbf{4}$ were attempted, the final separation proved extremely challenging, lowering the isolated yields. Thus, the precipitation of 7.T1 and 8.T2 after reduction was a crucial step to remove side products. The final covalent organic macrocycles 9 and 10 were stable over weeks when stored in the solid state but slowly degraded in chlorinated solvents. Despite the fast and efficient reduction of imine bonds reported herein with only limited equivalents of borane (2.0-2.5 equiv of $\mathrm{BH}_{3} /$ imine), only rare examples of imine reduction with this inexpensive and easy-to-handle reducing agent have been reported. ${ }^{27}$

Higher-order supramolecular assembly of macrocycles. When 1, 4 and $\mathrm{Pd}^{\mathrm{II}}$ reacted in the presence of naphthalene diimide (NDI)-based template $\mathbf{T 3}$, a triply-bridged dimer of trimeric macrocycles $\mathbf{5}_{2} \cdot \mathbf{T}_{3}$ was observed to form (Scheme 3). When less T3 was employed, free $\mathbf{5} \cdot\left(\mathrm{CD}_{3} \mathbf{C N}\right)_{3}$ and $5_{2} \cdot \mathrm{T}_{3}$ were observed as the principal products (see ${ }^{1} \mathrm{H}$ NMR spectra in Figure S53). This observation suggests the presence of positive cooperativity in the binding of $\mathbf{T} 3$ by 5. ${ }^{28}$ Crystals of $\mathbf{5}_{2} \cdot \mathrm{T}_{3}$ were grown by slow diffusion of benzene into an $\mathrm{MeCN}$ solution in the presence of $\mathrm{KSbF}_{6}(10$ equiv/Pd). The single-crystal X-ray structure (Scheme 3 ) shows that the macrocycles adopt a cone conformation, similar to the crystal structure of $5 \cdot(\mathrm{MeCN})_{3},{ }^{17}$ with the concave face pointing outward. The three bridging T3 ligands twist around the central $C_{3}$ axis, lending helicity to the complex in the solid state. Both right-handed and lefthanded helices were present in the crystal, related by inversion symmetry. The three NDI units enclose a tubular $98 \AA^{3}$ cavity which contains a $\mathrm{BF}_{4}^{-}$anion despite crystallization in the presence of excess $\mathrm{SbF}_{6}-{ }^{-29}$ The angles between phenylene rings around $\mathrm{Pd}^{\mathrm{II}}$ centers are in the range $\alpha=85-91^{\circ}$ which shows the bis(imino)pyridyl-Pd ${ }^{\mathrm{II}}$ moiety, again close to $90^{\circ}$. The ${ }^{1} \mathrm{H}$ NMR spectrum of $5_{2} \cdot \mathrm{T}_{3}$ in $\mathrm{CD}_{3} \mathrm{CN}$ at $25^{\circ} \mathrm{C}$ corresponds to a $D_{3 \mathrm{~h}}$ structure, which does not reflect the helicity observed in the solid state. VT NMR (Figure S51) showed desymmetrization at $-40{ }^{\circ} \mathrm{C}$, with a ${ }^{1} \mathrm{H}$ spectrum corresponding to the $D_{3}$-symmetric species observed in the solid state. Conversion between enantiomers 
thus occurred in solution with an activation barrier $\Delta \mathrm{G}^{\ddagger}=$ $52 \pm 2 \mathrm{~kJ} \mathrm{~mol}^{-1}$ at $0{ }^{\circ} \mathrm{C}$ (Figure S51). VT ${ }^{19} \mathrm{~F}$ NMR showed that the inclusion and release of $\mathrm{BF}_{4}^{-}$is rapid on the chemical shift timescale at $25^{\circ} \mathrm{C}$ but slow at $-40^{\circ} \mathrm{C}$, as indicated by the appearance of a peak for the included $\mathrm{BF}_{4}{ }^{-}$at low temperature (Figure S52).

Three-dimensional covalent cages. Considering the bis(imino)pyridyl-Pd ${ }^{\mathrm{II}}$ motif as a $90^{\circ}$ twofold connector, a corresponding threefold connector with $\sim 117^{\circ}$ angles ${ }^{30}$ could generate two distinct three-dimensional high-symmetry cages: a $\mathrm{Pd}_{6}$ structure with $T_{\mathrm{d}}$ symmetry, and a larger $\mathrm{Pd}_{12}$ architecture with $\mathrm{O}_{\mathrm{h}}$ symmetry (Figure 3). ${ }^{31}$
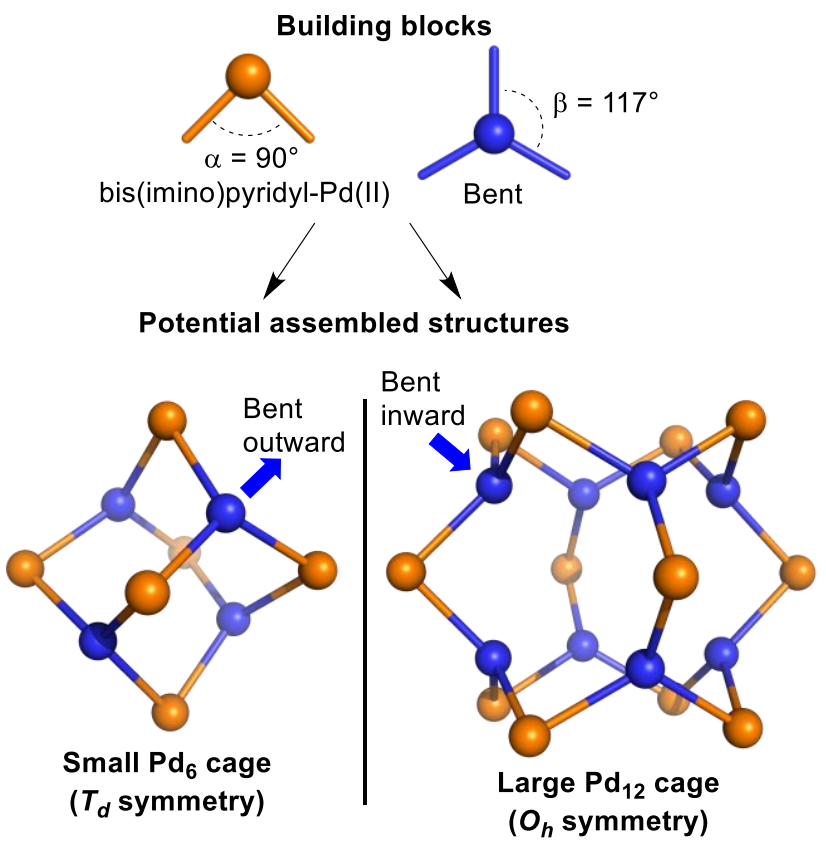

Figure 3. Expected structures for the assembly of $90^{\circ}$ bis(imino)pyridyl-PdII moiety with corresponding tris-anilines of appropriate geometry. The small $\mathrm{Pd}_{6}$ cage approximates a truncated tetrahedron, and the large $\mathrm{Pd}_{12}$ cage is cuboctahedral.

Considering that the ideal angle ${ }^{30}$ of $117^{\circ}$ is close to the $120^{\circ}$ of planar tris-anilines, we tested four planar and one pyramidal tris-anilines (Figures 4 and S73). The more rigid tris-anilines gave only traces of discrete species along with oligomeric products, as suggested by the presence of small sharp ${ }^{1} \mathrm{H}$ NMR signals along with more intense broad signals (Figure S73). This result is not surprising, as a fully planar tris-aniline, with an angle $\beta$ of $120^{\circ}$, would require an angle $\alpha$ of either $71^{\circ}$ or $109^{\circ}$ to form the small or large cage structures proposed in Figure 3, respectively. ${ }^{30}$ Such $\alpha$ values are outside of the range of angles adopted by the bis(imino)pyridyl-Pd"I building block studied herein.

The product mixture formed from the more flexible tris(4-aminophenyl)amine $\mathbf{1 l}$ had two sets of sharp peaks in the ${ }^{1} \mathrm{H}$ NMR spectrum, suggesting that the nitrogen atom in the ligand core can rehybridize in order to adopt the geometry required to form stable cages (Figure 4).
DOSY analysis indicated the two sets of peaks to correspond to structures having different sizes (Figure S61). As with their smaller congeners, the products having $\mathrm{MeCN}$ bound to the internally-facing $\mathrm{Pd}^{\mathrm{II}}$ coordination site were unstable under ESI-MS conditions. Replacement of MeCN with chloride increased the stability, which allowed successful analysis by ESI-MS (Figure S62).

We initially expected these products to correspond to the $\mathrm{Pd}_{6}$ and a $\mathrm{Pd}_{12}$ cages shown in Figure 3. The ${ }^{1} \mathrm{H}$ NMR and ESI-MS analyses indicated that the major species corresponded to the expected highly symmetrical $\left(T_{\mathrm{d}}\right) \mathrm{Pd}_{6}$ cage 12, but the minor species corresponded instead to an intermediate $\mathrm{Pd}_{9}$ cage $\mathbf{1 3}$ with $D_{3 \mathrm{~h}}$ symmetry (Figure 4 ), having 2 sets of ${ }^{1} \mathrm{H}$ NMR peaks in a 2:1 ratio.

Crystals of $\mathbf{1 2} \cdot \mathbf{C l}_{\mathbf{6}}$ were grown from the mixture of $\mathbf{1 2} \cdot \mathbf{C l}_{\mathbf{6}}$ and $\mathbf{1 3 .} \mathbf{C l}_{\mathbf{9}}$ by slow diffusion of benzene into an $\mathrm{MeCN}$ solution in the presence of $\mathrm{KAsF}_{6}$ (10 equiv/Pd) (Figure 4). The single-crystal X-ray data were of lower quality than for the other complexes reported herein, which we attributed partly to disorder around the phenylene rings. The three phenylene rings around each central nitrogen adopt a propeller shape with disorder observed between the righthanded and left-handed propellers. This propeller geometry has been observed for other self-assembled cages incorporating tris-aniline $11 .^{32}$ The X-ray data did not allow us to differentiate whether the crystal of $\mathbf{1 2} \cdot \mathbf{C l}_{\mathbf{6}}$ contained pure enantiomers (i.e. entirely right-handed and left-handed cages) randomly scattered, or if each cage within the crystal contained a random mixture of right- and left-handed propellers. For clarity, the crystal structure in Figure 4 is shown with only right-handed propeller units. The ${ }^{1} \mathrm{H}$ NMR spectra of cages 12 and $\mathbf{1 3}$ in acetonitrile at $25^{\circ} \mathrm{C}(400$ and $500 \mathrm{MHz}$ ) were consistent with fast rotation of the phenylene moieties on the NMR chemical shift time scale in solution.

The framework of $\mathbf{1 2}$ can be viewed as a truncated tetrahedron bearing four trigonal aromatic panels and four empty panels, with $\mathrm{Pd}^{\mathrm{II}}$ centers describing the vertices of an octahedron. These features recall the $\mathrm{Pd}_{6}(\operatorname{tris}(4-$ pyridyl)-1,3,5-triazine) ${ }_{4}$ coordination cages first reported by Fujita et al. in 1995 and productively studied since then. ${ }^{33}$ In comparison, $\mathbf{1 2} \cdot \mathbf{C l}_{6}$ shows shorter Pd-Pd distances than the purely coordination cage studied by Fujita (15.0-16.0 Å between antipodal Pd centers, and 10.9-11.5 $\AA$ for adjacent pairs of Pd ions in $\mathbf{1 2} \cdot \mathbf{C l}_{6}$ vs. $18.1-18.8 \AA$ and 12.7-13.4 $\AA$ for $\mathrm{Pd}_{6}{ }_{6}\left(\right.$ tris(4-pyridyl)-1,3,5-triazine) ${ }_{4}$ with various bidentate peripheral ligands ${ }^{33}$ ). In addition to the smaller size of 12, it differs from the Fujita cage in having a covalent framework, trans-coordinated imines around each Pd ${ }^{\mathrm{II}}$, and an extra single binding site per Pd ${ }^{\mathrm{II}}$ center, all oriented towards the central cavity of 12 . The angles between phenylene rings around $\mathrm{Pd}^{\mathrm{II}}$ centers are in the range $\alpha=90-95^{\circ}$, in common with the other structures that incorporate this motif. We could not obtain single crystals of the larger $\mathbf{1 3} \cdot \mathbf{C l}$ g cage, but a PM3 model minimized to a structure having $\alpha=89-95^{\circ}$ (Figure 4 , and Table S8). ${ }^{23}$ 


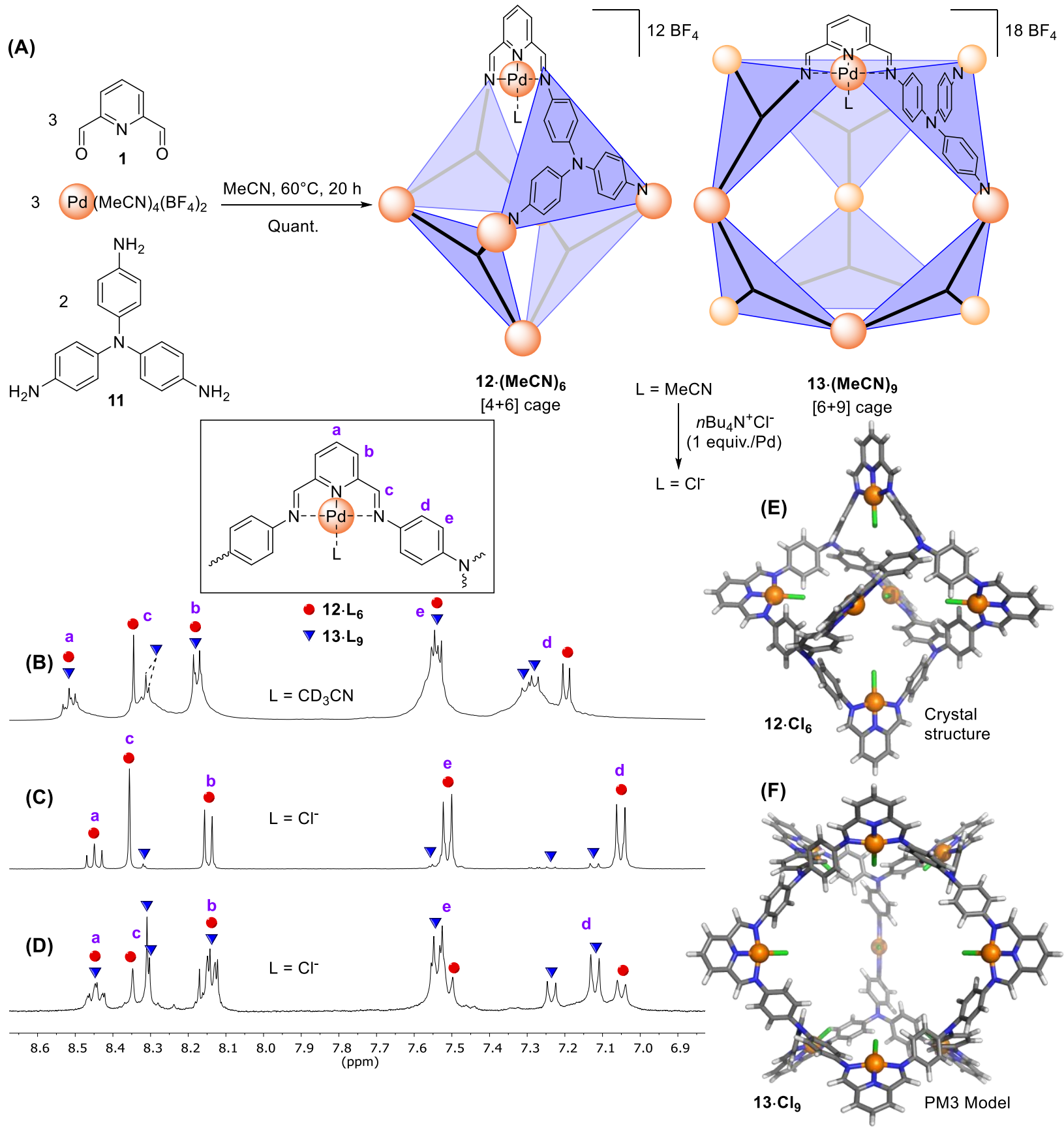

Figure 4. (A) Synthesis of cages $\mathbf{1 2}[4+6]$ and $\mathbf{1 3}[6+9]$. ${ }^{1} \mathrm{H}$ NMR spectra $\left(\mathrm{CD}_{3} \mathrm{CN}, 25^{\circ} \mathrm{C}\right)$ of $(\mathrm{B}) \mathbf{1 2} \cdot(\mathbf{M e C N})_{6}$ and $\mathbf{1 3} \cdot(\mathrm{MeCN})_{\mathbf{9}}($ anion $=\mathrm{BF}_{4^{-}}, 500 \mathrm{MHz}$ ), (C) enriched 12. $\mathbf{C l}_{\mathbf{6}}$ from first extraction (anion = $\mathrm{NTf}_{2^{-}}, 400 \mathrm{MHz}$ ), and (D) enriched $\mathbf{1 3} \cdot \mathbf{C l} \mathbf{l}_{\mathbf{9}}$ from fifth extraction (anion $=\mathrm{NTf}_{2}-400 \mathrm{MHz}$ ). (E) Crystal structure of $\mathbf{1 2} \cdot \mathbf{C l}_{6}$ : anions and free solvent molecules are not shown for clarity; right-handed propellers are arbitrarily shown. (F) PM3 model of $\mathbf{1 3} \cdot \mathbf{C l}_{9}$ : right-handed propellers were chosen arbitrarily for the optimization.

In addition to chloride, the anions bromide, iodide and thiocyanate were also tested as prospective inner ligands. Solutions of $\mathbf{1 2} \cdot(\mathrm{MeCN})_{6}$ and $\mathbf{1 3} \cdot(\mathrm{MeCN})_{9}$ were treated with these anions as $n \mathrm{Bu}_{4} \mathrm{~N}^{+}$salts (Figure S72). Bromide provided $\mathbf{1 2} \cdot \mathbf{B r}_{6}$ and $\mathbf{1 3} \cdot \mathbf{B r}$, which had sharp ${ }^{1} \mathrm{H}$ NMR spectra at similar chemical shifts to $\mathbf{1 2} \cdot \mathbf{C l}_{\mathbf{6}}$ and $\mathbf{1 3 \cdot} \cdot \mathbf{C l}_{\mathbf{9}}$, but the bromide adducts were not stable enough for ESI-MS analyses. Both the chloride and bromide adducts of 12 and 13 remained stable in solution in $\mathrm{MeCN}$ over weeks at $25^{\circ} \mathrm{C}$ and overnight at $60^{\circ} \mathrm{C}$; heating for longer was not tested. In contrast, iodide and thiocyanate led to broadened ${ }^{1} \mathrm{H}$
NMR signals and precipitation over a period of hours. We infer that the larger sizes of these two anions may lead to steric clashes with the proximate phenyl groups, thus destabilizing the structures.

We were not able to separate cages $\mathbf{1 2}$ and $\mathbf{1 3}$ using a sizeexclusion column due to their poor solubility in the solvents used as eluent. The mixture of $12 \cdot(\mathrm{MeCN})_{6}$ and 13. $(\mathrm{MeCN})_{9}$ with $\mathrm{BF}_{4}^{-}$as counteranions could be isolated in the solid state and subsequently dissolved in $\mathrm{MeCN}$, but 
the mixture of $\mathbf{1 2} \cdot \mathbf{C l}_{\mathbf{6}}$ and $\mathbf{1 3} \cdot \mathbf{C l}_{\mathbf{9}}$ did not redissolve after drying. This lack of solubility was surprising considering that the complexes were not observed to precipitate from $\mathrm{MeCN}$ over one month at $25^{\circ} \mathrm{C}$, suggesting slow kinetics of dissolution for the dry material rather than low solubility. We therefore replaced the $\mathrm{BF}_{4}{ }^{-}$counter anions with bulkier $\mathrm{NTf}_{2}{ }^{-}$to accelerate dissolution. Intriguingly, the triflimide salt of $\mathbf{1 2} \cdot \mathbf{C l}_{\mathbf{6}}$ dissolved more rapidly than $\mathbf{1 3} \cdot \mathbf{C l}_{\mathbf{9}}$, which allowed sample enrichment through multiple washes with fresh MeCN (see Figures 4C, 4D and Supporting Information, section 1.11). Although $\mathbf{1 2} \cdot(\mathrm{MeCN})_{6}$ and 13-(MeCN) ${ }_{9}$ exhibited dynamic imine exchange (see below), no conversion was observed between $\mathbf{1 2} \cdot \mathbf{C l}_{6}$ and 13. $\mathrm{Cl}_{9}$ at $25^{\circ} \mathrm{C}$ in $\mathrm{MeCN}$ over one month.

We then investigated the effects of multivalent templates coordinating to the inward-facing $\mathrm{Pd}^{\mathrm{II}}$ sites of these three-dimensional cage structures. Mixtures of 12. $(\mathrm{MeCN})_{6}$ and 13. $(\mathrm{MeCN})_{9}$ were treated with $\mathrm{Tl}$ and $\mathrm{T} 2$ to see if they would selectively template $\mathrm{Pd}_{6}$ cage $12, \mathrm{Pd}_{9}$ cage 13, or the larger $\mathrm{Pd}_{12}$ cage of Figure 3 , which contain faces consisting of trimeric and tetrameric macrocycles. Numerous attempts using different amounts of template did not induce selectivity, leading instead to highly complex NMR and ESI-MS spectra (see Table S1). As the 5.T1 and 6.T2 macrocycles described above adopted non-cone conformers, we infer that the analogous macrocyclic subunits of the structures formed from 11 with templates Tl and T2 would also form non-cone conformers, which are not configured for cage formation.

We then tested the ability of NDI-based bis(pyridine) T3 to selectively template cage $13 \cdot \mathbf{T 3}_{3}$ (Scheme 4 ), because cage $\mathbf{B}$ contains a pair of $\mathrm{Pd}_{3}$ rings that are held in a similar configuration as in the bridged macrocycles of $\mathbf{5}_{2} \cdot \mathbf{T}_{3}$. Our initial attempts mixing $\mathbf{1}, \mathbf{1},\left[\mathrm{Pd}(\mathrm{MeCN})_{4}\right]\left(\mathrm{BF}_{4}\right)_{2}$ and $\mathbf{T} 3$ in a 9:6:6:3 ratio were unsuccessful (see Table $\mathrm{Sl}$ ), but addition of $n \mathrm{Bu}_{4} \mathrm{~N}^{+} \mathrm{Cl}^{-}\left(0.33\right.$ equiv/Pd) provided $13 \cdot \mathrm{T3}_{3} \cdot \mathrm{Cl}_{3}$ in $c a$. $10 \%$ yield according to NMR and ESI-MS analyses (Scheme 4 and Figures $\mathrm{S} 64$ and S65). PM3 models of 13.T3 $\cdot(\mathrm{MeCN})_{3}$ and $\mathbf{1 3} \cdot \mathrm{T}_{3} \cdot \mathrm{Cl}_{3}$ suggested that the internal $\mathrm{MeCN}$ ligands in the former would clash with the three central T3, whereas chloride in the latter complex would not (Scheme 4 and Table S9). ${ }^{23}$ We infer that this lack of clash in $\mathbf{1 3} \cdot \mathbf{T 3}_{3} \cdot \mathbf{C l}_{3}$ underpins the importance of chloride for the formation of this cage.

The ${ }^{1} \mathrm{H}$ NMR spectrum of crude $\mathbf{1 3} \cdot \mathbf{T 3}_{3} \cdot \mathrm{Cl}_{3}$ clearly shows the 17 signals expected for the $D_{3 \mathrm{~h}}$-symmetric product, along with a set of broad signals that could correspond to oligomeric byproducts. Comparison between the integrals of the $\mathbf{1 3} \cdot \mathbf{T 3}_{3} \cdot \mathrm{Cl}_{3}$ product and $n \mathrm{Bu}_{4} \mathrm{~N}^{+}$signals was used to gauge the yield, which was never observed to increase beyond $11 \%$. Different attempted optimizations included running the reaction at $150^{\circ} \mathrm{C}$ in a microwave reactor, and changing the order of addition of the starting materials (Table Sl). Isolation of $\mathbf{1 3} \cdot \mathbf{T 3}_{3} \cdot \mathbf{C l}_{3}$ from the putative oligomer co-products by size-exclusion column was prevented by the lack of product solubility in the solvents used as eluents. The templated formation of a single discrete species nonetheless shows the potential for templation involving the bis(imino)pyridyl-Pd ${ }^{\text {II }}$ building block for the construction of covalent metallo-cages. Careful optimization of template geometry may enable the yields of specific cage products to be further improved.

\section{Scheme 4 . Synthesis of templated cage $13 \cdot \mathrm{T}_{3} \cdot \mathrm{Cl}_{3} \cdot{ }^{\mathrm{a}}$}

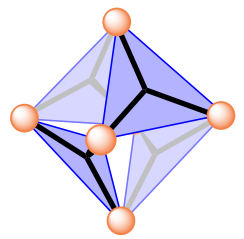

12. $(\mathrm{MeCN})_{6}\left(\mathrm{BF}_{4}\right)_{12}$
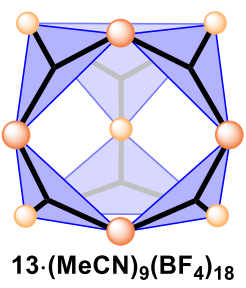

1) $n \mathrm{Bu}_{4} \mathrm{~N}^{+} \mathrm{Cl}^{-}(0.33$ equiv./Pd)

2) $\mathrm{T} 3$ ( 0.33 equiv./Pd)

3) $\mu$-wave, $150^{\circ} \mathrm{C}, 30 \mathrm{~min}$. $\mathrm{MeCN}$

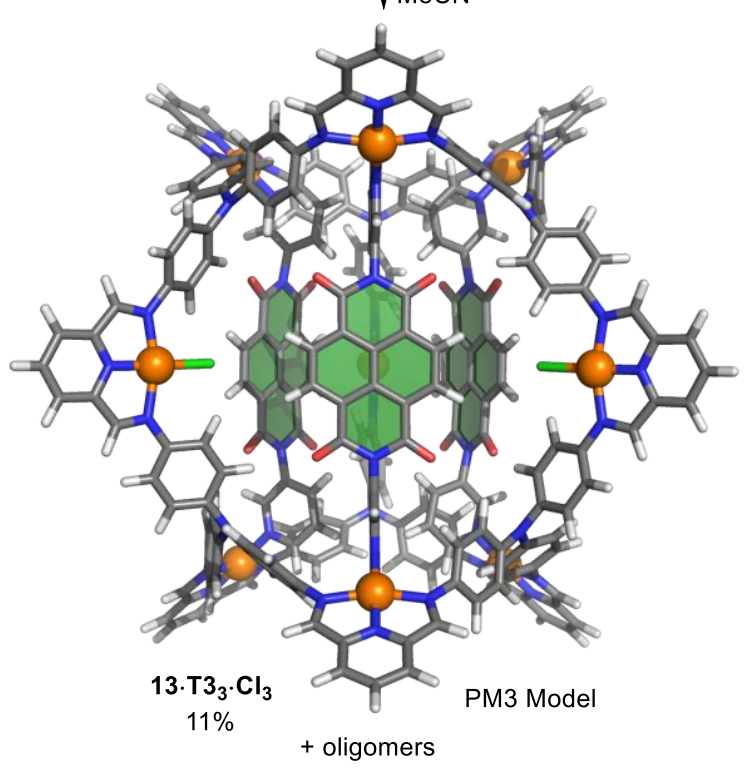

a The PM3 model was optimized with right-handed triphenylamine propellers, arbitrarily.

The mixture of $\mathbf{1 2} \cdot \mathbf{C l}_{\mathbf{6}}$ and $\mathbf{1 3} \cdot \mathbf{C l}_{\mathbf{9}}$ was subjected to the optimized imine reduction conditions used for macrocycles 5.T1 and 6.T2 (Figures S66-S68). ESI-MS monitoring of the reaction showed effective reduction of all imine bonds, but NMR spectra of the crude product were indecipherable, as expected considering the numerous stereoisomers originating from the $\mathrm{NH}$ stereocenters of the reduced cages, as was observed in the cases of 7.T1 and 8.T2. Treatment with ethylenediamine in DMSO led to species with broad ${ }^{1} \mathrm{H}$ NMR signals in the anticipated chemical shift regions for the demetallated and reduced cages (Figure S68). We infer the broadness to be a consequence of slow interconversion between different hydrogen-bonded conformers. Precipitation of the demetallated cages by adding water afforded a solid which only dissolved in highly acidic aqueous solutions (i.e. $\left.>4 \mathrm{M} \mathrm{HCl}_{(\mathrm{aq})}\right)$. Degradation appeared to accompany dissolution, as no trace of the product was observed by ${ }^{1} \mathrm{H}$ NMR in $\mathrm{DCl} / \mathrm{D}_{2} \mathrm{O}$. The product was also suspended in 17 organic solvents, including chlorinated, aromatic, aliphatic, polar, apolar, protic and aprotic solvents, with no 


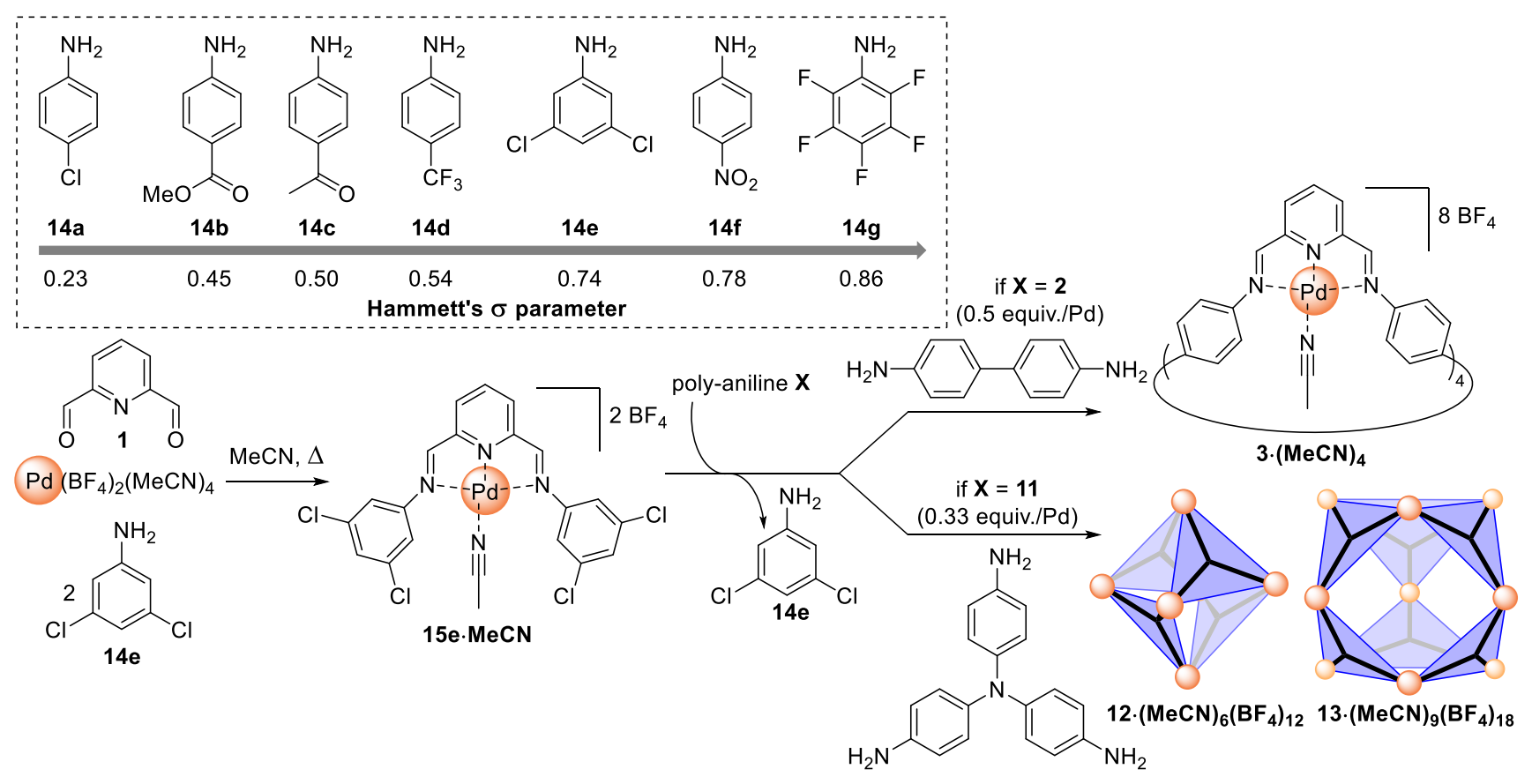

Figure 5. Imine exchange by poly-anilines on mononuclear bis(imino)pyridyl-PdII 15e led to larger assemblies. Inset: List of electron-poor mono-anilines tested and their Hammett $\sigma$ parameters; ${ }^{34}$ for $\mathbf{1 4 g}$ the unreported fluorine $\sigma_{\text {ortho }}$ value was approximated by the known $\sigma_{\text {para }}$.

evidence of dissolution (see Supporting Information, section 1.13). This lack of solubility prevented further characterization, purity and yield determination. Building blocks that incorporate solubilizing moieties may allow for future covalent organic cages to be prepared.

Aniline exchange. Dynamic-covalent imines can exchange aniline residues with free anilines. ${ }^{35}$ The side of the equilibrium favored depends upon the stoichiometry and relative nucleophilicities of the anilines. Aniline exchange was previously used to modify the periphery of self-assembled structures ${ }^{36}$ but, to the best of our knowledge, has not yet been applied to the construction of assemblies whose cores consist of multi-topic aniline residues displacing mono-anilines, as reported herein. For the previously-reported peripheral modifications, excess aniline could be added to insure complete exchange. In the present case, however, such an excess would be impractical as it would result in a mixture of products that incorporated multitopic anilines that had not fully reacted.

We thus screened several electron-poor mono-anilines 14a-14g (Figure 5) for the formation of the corresponding bis(imino)pyridyl-Pd ${ }^{\mathrm{II}}$ complexes $\mathbf{1 5 a}-\mathbf{1 5 g}$. We then evaluated the efficiency of the displacement of these different electron-poor aniline residues by the more electron-rich bis-aniline 2 to form macrocycle 3. Aniline 14e (Figure 5) was observed to give the best result; full details are provided in Figures S74-S77 and the accompanying text.

The electron densities of the mono-anilines were assessed based on the Hammett $\sigma$ parameters of their substituents. ${ }^{34}$ Mono-anilines 14a-14f formed the corresponding bis(imino)pyridyl-Pd ${ }^{\mathrm{II}}$ complexes $\mathbf{1 5 a} \mathbf{a} \mathbf{- 1 5 f}$ cleanly, as gauged by ${ }^{1} \mathrm{H}$ NMR (Figure S74). The most electron-deficient aniline $14 \mathrm{~g}$ failed to generate the imine complex, however.

The displacement of the aniline residues $\mathbf{1 4 a - 1 4 f}$ by benzidine 2 occurred in better yield as the electron-deficiency of the leaving aniline increased (Figure S77). The monoanilines that yielded macrocycle 3 the most efficiently were thus 3,5-dichloroaniline 14e and 4-nitroaniline 14f, which possess a similar degree of electron-deficiency according to their Hammett $\sigma$ parameters $\left(\sigma_{14 \mathrm{e}}=0.74\right.$ vs. $\left.\sigma_{14 \mathrm{f}}=0.78\right)$.

The corresponding mononuclear complexes $15 \mathbf{e}$ and $\mathbf{1 5 f}$ were treated with tris-aniline $\mathbf{1 1}$ to evaluate the formation of cages $\mathbf{1 2}$ and $\mathbf{1 3}$ through aniline exchange. Both reactions afforded the desired cages (Figures S78 and S79) but 15f also led to an extra set of unidentified ${ }^{1} \mathrm{H}$ NMR peaks. Aniline 14e was therefore selected as the best aniline leaving group for aniline exchange. Templated cage $\mathbf{1 3} \cdot \mathbf{T}_{3} \cdot \mathbf{C l}_{3}$ was also successfully prepared through aniline exchange albeit in low yield, similarly to the direct synthesis (Figure S80).

\section{Conclusions}

The bis(imino)pyridyl-Pd ${ }^{\text {II }}$ motif thus serves as a $90^{\circ}$ building block to generate a wide variety of dynamic-covalent metal-containing macrocycles and cages. This motif provides some flexibility, adopting angles that range from $85-97^{\circ}$. The free coordination site on the $\mathrm{Pd}^{\mathrm{II}}$ center oriented to the inside of the assemblies allows the stability and shape of the covalent assemblies to be tuned, as well as permitting covalent assemblies to be bridged by multitopic ligands in order to form more complex supramolecular assemblies. Efficient imine reduction conditions were developed to afford covalent organic macrocycles in good yields from these multi-imino $\mathrm{Pd}^{\mathrm{II}}$ complexes. Future work 
will focus upon the extension of these methods to generate larger structures and the use of other metal cations with similar tridentate building blocks, ${ }^{37}$ which could lead to different angles and more free coordination sites. The imine-containing macrocycles and cages reported herein could also be good candidates to undergo oxidation to amides, as recently reported by Mastalerz et al. in the context of another imine-based covalent cage. ${ }^{38}$ Furthermore, we will explore the potential of the new reduced and demetallated macrocycles and cages for guest recognition, including anionic guests via hydrogen bonding and metal cations via coordination to the tridentate sites.

\section{ASSOCIATED CONTENT}

Supporting Information. Experimental section, NMR spectra, mass spectra, geometry optimized models, crystallographic details and single-crystal XRD structures of 3.(MeCN) $)_{4}$ (CCDC 1903235), 52.T33 (CCDC 1903237) and $\mathbf{1 2} \cdot \mathbf{C l}_{\mathbf{6}}$ (CCDC 1903236) are available as supplementary material. This material is available free of charge via the Internet at http://pubs.acs.org.

\section{AUTHOR INFORMATION}

\section{Corresponding Author}

*jrn34@cam.ac.uk

\section{ORCID}

Roy Lavendomme: 0000-0001-6238-8491

Tanya K. Ronson: 0000-0002-6917-3685

Jonathan R. Nitschke: 0000-0002-4060-5122

\section{Notes}

The authors declare no competing financial interest.

\section{ACKNOWLEDGMENT}

This study was supported by the European Research Council (695009) and the UK Engineering and Physical Sciences Research Council (EPSRC, EP/P027067/1). R.L. was funded by the Fondation Wiener-Anspach postdoctoral fellowship. We thank Diamond Light Source for time on Beamline I19 (MT15768). We thank the National Mass Spectrometry Facility at the University of Swansea for high-resolution mass spectrometry analyses of 7·T1, 8.T2, 9 and 10.

\section{REFERENCES}

(1) (a) Szejtli, J. Introduction and General Overview of Cyclodextrin Chemistry. Chem. Rev. 1998, 98, 1743-1753. (b) Lagona, J.; Mukhopadhyay, P.; Chakrabarti, S.; Isaacs, L. The Cucurbit[n] uril Family. Angew. Chem. Int. Ed. 2005, 44, 4844-4870. (c) Xue, M.; Yang, Y.; Chi, X.; Zhang, Z.; Huang, F. Pillararenes, A New Class of Macrocycles for Supramolecular Chemistry. Acc. Chem. Res. 2012, 45, 1294-1308. (d) Calixarenes and Beyond; Neri, P., Sessler, J. L., Wang, M.-X., Eds., Springer: Switzerland, 2016. (e) Hiroto, S.; Miyake, Y.; Shinokubo, H. Synthesis and Functionalization of Porphyrins through Organometallic Methodologies. Chem. Rev. 2017, 117, 2910-3043. (f) Assaf, K. I.; Nau, W. M. Cucurbiturils: from synthesis to high-affinity binding and catalysis. Chem. Soc. Rev. 2015, 44, 394-418. (g) Lee, S.; Chen, C.-H.; Flood, A. H. A pentagonal cyanostar macrocycle with cyanostilbene $\mathrm{CH}$ donors binds anions and forms dialkylphosphate [3]rotaxanes. Nat. Chem. 2013, 5, 704-710.
(2) (a) Šolomek, T.; Powers-Riggs, N. E.; Wu, Y.-L.; Young, R. M.; Krzyaniak, M. D.; Horwitz, N. E.; Wasielewski, M. R. Electron Hopping and Charge Separation within a Naphthalene-1,4:5,8bis(dicarboximide) Chiral Covalent Organic Cage. J. Am. Chem. Soc. 2017, 139, 3348-3351. (b) Wang, X.; Wang, Y.; Yang, H.; Fang, H.; Chen, R.; Sun, Y.; Zheng, N.; Tan, K.; Lu, X.; Tian, Z.; Cao, X. Assembled molecular face-rotating polyhedra to transfer chirality from two to three dimensions. Nat. Commun. 2016, 7, 12469. (c) Collins, M. S.; Phan, N.-M.; Zakharov, L. N.; Johnson, D. W. Coupling Metaloid-Directed Self-Assembly and Dynamic Covalent Systems as a Route to Large Organic Cages and Cyclophanes. Inorg. Chem. 2018, 57, 3486-3496. (d) Greenaway, R. L.; Santolini, V.; Bennison, M. J.; Alston, B. M.; Pugh, C. J.; Little, M. A.; Miklitz, M.; Eden-Rump, E. G. B.; Clowes, R.; Shakil, A.; Cuthbertson, H. J.; Armstrong, H.; Briggs, M. E.; Jelfs, K. E.; Cooper, A. I. Highthroughput discovery of organic cages and catenanes using computational screening fused with robotic synthesis. Nat. Commun. 2018, 9, 2849. (e) Song, Q.; Jiang, S.; Hasell, T.; Liu, M.; Sun, S.; Cheetham, A. K.; Sivaniah, E.; Cooper, A. I. Porous Organic Cage Thin Films and Molecular-Sieving Membranes. Adv. Mater. 2016, 28, 2629-2637. (f) Mukhopadhyay, R. D.; Kim, Y.; Koo, J.; Kim, K. Porphyrin Boxes. Acc. Chem. Res. 2018, 51, 2730-2738. (g) Mastalerz, M. Porous Shape-Persistent Organic Cage Compounds of Different Size, Geometry, and Function. Acc. Chem. Res. 2018, 51, 2411-2422. (h) Tozawa, T.; Jones, J. T. A.; Swamy, S. I.; Jiang, S.; Adams, D. J.; Shakespeare, S.; Clowes, R.; Bradshaw, D.; Hasell, T.; Chong, S. Y.; Tang, C.; Thompson, S.; Parker, J.; Trewin, A.; Bacsa, J.; Slawin, A. M. Z.; Steiner, A.; Cooper, A. I. Porous organic cages. Nat. Mater. 2009, 8, 973-978. (i) Giri, N.; Del Pópolo, M. G.; Melaugh, G.; Greenaway, R. L.; Rätzke, K.; Koschine, T.; Pison, L.; Costa Gomes, M. F.; Cooper, A. I.; James, S. L. Liquids with permanent porosity. Nature 2015, 527, 216-220. (j) Zhang, G.; Mastalerz, M. Organic cage compounds - from shape-persistency to function. Chem. Soc. Rev. 2014, 43, 1934-1947. (k) Zhang, D.; Martinez, A.; Dutasta, J.-P. Emergence of Hemicryptophanes: From Synthesis to Applications for Recognition, Molecular Machines, and Supramolecular Catalysis. Chem. Rev. 2017, 117, 4900-4942.

(3) (a) Acharyya, K.; Mukherjee, P. S. A fluorescent organic cage for picric acid detection. Chem. Commun. 2014, 50, 15788-15791. (b) Kang, S. O.; Day, V. W.; Bowman-James, K. Fluoride: Solutionand Solid-State Structural Binding Probe. J. Org. Chem. 2010, 75, 277-283. (c) Rios, P.; Carter, T. S.; Mooibroek, T. J.; Crump, M. P.; Lisbjerg, M.; Pittelkow, M.; Supekar, N. T.; Boons, G.-J.; Davis, A. P. Synthetic Receptors for the High-Affinity Recognition of OGlcNAc Derivatives. Angew. Chem. Int. Ed. 2016, 55, 3387-3392. (d) Tromans, R. A.; Carter, T. S.; Chabanne, L.; Crump, M. P.; Li, H.; Matlock, J. V.; Orchard, M. G.; Davis, A. P. A biomimetic receptor for glucose. Nat. Chem. 2019, 11, 52-56. (e) Akine, S.; Miyashita, M.; Nabeshima, T. A Metallo-molecular Cage That Can Close the Apertures with Coordination Bonds. J. Am. Chem. Soc. 2017, 139, 4631-4634. (f) Liu, Y.; Shen, J.; Sun, C.; Ren, C.; Zeng, H. Intramolecularly Hydrogen-Bonded Aromatic Pentamers as Modularly Tunable Macrocyclic Receptors for Selective Recognition of Metal Ions. J. Am. Chem. Soc. 2015, 137, 12055-12063. (g) Yawer, M. A.; Havel, V.; Sindelar, V. A Bambusuril Macrocycle that Binds Anions in Water with High Affinity and Selectivity. Angew. Chem. Int. Ed. 2015, 54, 276-279. (h) Kang, S. O.; Llinares, J. M.; Powell, D.; VanderVelde, D.; Bowman-James, K. New Polyamide Cryptand for Anion Binding. J. Am. Chem. Soc. 2003, 125, 10152-10153.

(4) (a) Shi, Y.; Cai, K.; Xiao, H.; Liu, Z.; Zhou, J.; Shen, D.; Qiu, Y.; Guo, Q.-H.; Stern, C.; Wasielewski, M. R.; Diederich, F.; Goddard III, W. A.; Stoddart, J. F. Selective Extraction of $\mathrm{C}_{70}$ by a Tetragonal Prismatic Porphyrin Cage. J. Am. Chem. Soc. 2018, 140, 13835-13842. (b) Delahousse, G.; Lavendomme, R.; Jabin, I.; Agasse, V.; Cardinael, P. Calixarene-based stationary phases for chromatography. Curr. Org. Chem. 2015, 19, 2237-2249. 
(5) (a) Roy, B.; Devaraj, A.; Saha, R.; Jharimune, S.; Chi, K.-W.; Mukherjee, P. S. Catalytic Intramolecular Cycloaddition Reactions by Using a Discrete Molecular Architecture. Chem.-Eur. J. 2017, 23, 15704-15712. (b) Das, P.; Kumar, A.; Howlader, P.; Mukherjee, P. S. A Self-Assembled Trigonal Prismatic Molecular Vessel for Catalytic Dehydration Reactions in Water. Chem.-Eur. J. 2017, 23, 12565-12574. (c) Mondal, B.; Acharyya, K.; Howlader, P.; Mukherjee, P. S. Molecular Cage Impregnated Palladium Nanoparticles: Efficient, Additive-Free Heterogeneous Catalysts for Cyanation of Aryl Halides. J. Am. Chem. Soc. 2016, 138, 1709-1716. (d) Mondal, B.; Mukherjee, P. S. Cage Encapsulated Gold Nanoparticles as Heterogeneous Photocatalyst for Facile and Selective Reduction of Nitroarenes to Azo Compounds. J. Am. Chem. Soc. 2018, 140, 12592-12601.

(6) Mattiuzzi, A.; Jabin, I.; Mangeney, C.; Roux, C.; Reinaud, O.; Santos, L.; Bergamini, J.-F.; Hapiot, P.; Lagrost, C. Electrografting of calix[4] arenediazonium salts to form versatile robust platforms for spatially controlled surface functionalization. Nat. Commun. 2012, 3, 1130

(7) (a) The Nature of the Mechanical Bond: From Molecules to Machines; Bruns, C. J., Stoddart, J. F., Eds., Wiley: Hoboken, New Jersey, 2017. (b) Collin, J.-P.; Dietrich-Buchecker, C.; Gaviña, P.; Jimenez-Molero, M. C.; Sauvage, J.-P. Shuttles and Muscles: Linear Molecular Machines Based on Transition Metals. Acc. Chem. Res. 2001, 34, 477-487. (c) Jamieson, E. M. G.; Modicom, F.; Goldup, S. M. Chirality in rotaxanes and catenanes. Chem. Soc. Rev. 2018, 47, 5266-5311.

(8) (a) Template Synthesis of Macrocyclic Compounds; Gerbeleu, N. V., Arion, V. B., Burgess, J., Eds., Wiley-VCH: Weinheim, 1999. (b) Mirzaei, S.; Wang, D.; Lindeman, S. V.; Sem, C. M.; Rathore, R. Highly Selective Synthesis of Pillar[n]arene $(n=5,6)$. Org. Lett. 2018, 20, 6583-6586. (c) Bols, P. S.; Anderson, H. L. Template-Directed Synthesis of Molecular Nanorings and Cages. Acc. Chem. Res. 2018, 51, 2083-2092.

(9) (a) Jin, Y.; Wang, Q.; Taynton, P.; Zhang, W. Dynamic Covalent Chemistry Approaches Toward Macrocycles, Molecular Cages, and Polymers. Acc. Chem. Res. 2014, 47, 1575-1586. (b) Ono, K.; Iwasawa, N. Dynamic Behavior of Covalent Organic Cages. Chem.-Eur. J. 2018, 24, 17856-17868. (c) Mastalerz, M. Shape-Persistent Organic Cage Compounds by Dynamic Covalent Bond Formation. Angew. Chem. Int. Ed. 2010, 49, 5042-5053.

(10) (a) Acharyya, K.; Mukherjee, P. S. Organic Imine Cages: Molecular Marriage and Applications. Angew. Chem. Int. Ed. 2019, 58, 8640-8653. (b) Lauer, J. C.; Zhang, W.-S.; Rominger, F.; Schröder, R. R.; Mastalerz, M. Shape-Persistent [4+4] Imine Cages with a Truncated Tetrahedral Geometry. Chem.-Eur. J. 2018, 24, 18161820. (c) Beaudoin, D.; Rominger, F.; Mastalerz, M. Chiral SelfSorting of [2+3] Salicylimine Cage Compounds. Angew. Chem. Int. Ed. 2017, 56, 1244-1248. (d) Jiao, T.; Chen, L.; Yang, D.; Li, X.; Wu, G.; Zeng, P.; Zhou, A.; Yin, Q.; Pan, Y.; Wu, B.; Hong, X.; Kong, X.; Lynch, V. M.; J. L. Sessler, Li, H. Trapping White Phosphorus within a Purely Organic Molecular Container Produced by Imine Condensation. Angew. Chem. Int. Ed. 2017, 56, 14545-14550.

(11) (a) Elbert, S. M.; Regenauer, N. I.; Schindler D.; Zhang, W.S.; Rominger, F.; Schröder, R. R.; Mastalerz, M. Shape-Persistent Tetrahedral [4+6] Boronic Ester Cages with Different Degrees of Fluoride Substitution. Chem.-Eur. J. 2018, 24, 11438-11443. (b) Ono, K.; Shimo, S.; Takahashi, K.; Yasuda, N.; Uekusa, H.; Iwasawa, N. Dynamic Interconversion between Boroxine Cages Based on Pyridine Ligation. Angew. Chem. Int. Ed. 2018, 57, 3113-3117.

(12) Quaglio, D.; Zappia, G.; De Paolis, E.; Balducci, S.; Botta, B.; Ghirga, F. Olefin metathesis reaction as a locking tool for macrocycle and mechanomolecule construction. Org. Chem. Front. 2018, 5, 3022-3055.

(13) (a) Wang, Q.; Yu, C.; Zhang, C.; Long, H.; Azarnoush, S.; Jin, Y.; Zhang, W. Dynamic covalent synthesis of ar- yleneethynylene cages through alkyne metathesis: dimer, tetramer, or interlocked complex? Chem. Sci. 2016, 7, 3370-3376. (b) Lee, S.; Yang, A.; Moneypenny II, T. P.; Moore, J. S. Kinetically Trapped Tetrahedral Cages via Alkyne Metathesis. J. Am. Chem. Soc. 2016, 138, 2182-2185.

(14) (a) Fujita, M. Metal-directed self-assembly of two- and three-dimensional synthetic receptors. Chem. Soc. Rev. 1998, 27, 417-425. (b) Leininger, S.; Olenyuk, B.; Stang, P. J. Self-Assembly of Discrete Cyclic Nanostructures Mediated by Transition Metals. Chem. Rev. 2000, 100, 853-908. (c) Seidel, S. R.; Stang, P. J. HighSymmetry Coordination Cages via Self-Assembly. Acc. Chem. Res. 2002, 35, 972-983. (d) Chakrabarty, R.; Mukherjee, P. S.; Stang, P. J. Supramolecular Coordination: Self-Assembly of Finite Two- and Three-Dimensional Ensembles. Chem. Rev. 2011, 111, 6810-6918. (e) Zhang, D.; Ronson, T. K.; Nitschke, J. R. Functional Capsules via Subcomponent Self-Assembly. Acc. Chem. Res. 2018, 51, 2423 2436. (f) McConnell, A. J.; Wood, C. S.; Neelakandan, P. P.; Nitschke, J. R. Stimuli-Responsive Metal-Ligand Assemblies. Chem. Rev. 2015, 115, 7729-7793. (g) Zhou, X.-P.; Liu, J.; Zhan, S.Z.; Yang, J.-R.; Li, D.; Ng, K.-M.; Sun, R. W.-Y.; Che, C.-M. A HighSymmetry Coordination Cage from 38- or 62-Component Self-Assembly. J. Am. Chem. Soc. 2012, 134, 8042-8045. (h) Han, Y.-F.; Jin, G.-X. Half-Sandwich Iridium- and Rhodium-based Organometallic Architectures: Rational Design, Synthesis, Characterization, and Applications. Acc. Chem. Res. 2014, 47, 3571-3579. (i) Zhang, Y.-Y.; Shen, X.-Y.; Weng, L.-H.; Jin, G.-X. Octadecanuclear Macrocycles and Nonanuclear Bowl-Shaped Structures Based on Two Analogous Pyridyl-Substituted Imidazole-4,5-dicarboxylate Ligands. J. Am. Chem. Soc. 2014, 136, 15521-15524.

(15) (a) Debata, N. B.; Tripathy, D.; Chand, D. K. Self-assembled coordination complexes from various palladium(II) components and bidentate or polydentate ligands. Coord. Chem. Rev. 2012, 256, 1831-1945. (b) Fujita, M.; Tominaga, M.; Hori, A.; Therrien, B. Coordination Assemblies from a Pd(II)-Cornered Square Complex. Acc. Chem. Res. 2005, 38, 369-378. (c) Sakata, Y.; Yamamoto, R.; Saito, D.; Tamura, Y.; Maruyama, K.; Ogoshi, T.; Akine, S. Metallonanobelt: A Kinetically Stable Shape-Persistent Molecular Belt Prepared by Reversible Self-Assembly Processes. Inorg. Chem. 2018, 57, 15500-15506. (d) Samanta, D.; Gemen, J.; Chu, Z.; Diskin-Posner, Y.; Shimon, L. J. W.; Klajn, R. Reversible photoswitching of encapsulated azobenzenes in water. Proc. Natl. Acad. Sci. U. S. A. 2018, 115, 9379-9384. (e) Yamashina, M.; Kusaba, S.; Akita, M.; Kikuchi, T.; Yoshizawa, M. Cramming versus threading of long amphiphilic oligomers into a polyaromatic capsule. Nat. Commun. 2018, 9, 4227. (f) Fujita, D.; Ueda, Y.; Sato, S.; Mizuno, N.; Kumasaka, T.; Fujita, M. Self-assembly of tetravalent Goldberg polyhedra from 144 small components. Nature 2016, 540, 563-566. (g) Zhu, R.; Regeni, I.; Holstein, J. J.; Dittrich, B.; Simon, M.; Prévost, S.; Gradzielski, M.; Clever, G. H. Catenation and Aggregation of Multi-Cavity Coordination Cages. Angew. Chem. Int. Ed. 2018, 57, 13652-13656.

(16) Albéniz, A. C.; Espinet, P. Palladium: Inorganic \& Coordination Chemistry. In Encyclopedia of Inorganic and Bioinorganic Chemistry; Scott, R. A., Ed.; Wiley, 2011. doi:10.1002/9781119951438.eibc0164

(17) Browne, C.; Ronson, T. K.; Nitschke, J. R. Palladium-Templated Subcomponent Self-Assembly of Macrocycles, Catenanes, and Rotaxanes. Angew. Chem. Int. Ed. 2014, 53, 10701-10705.

(18) Related 2,6-bis(ketimino)pyridyl-Pd ${ }^{\mathrm{II}}$ mononuclear complexes reported by Liu et al. show similar structural properties; see: (a) Liu, P.; Zhou, L.; Li, X.; He, R. Bis(imino)pyridine palladium(II) complexes: Synthesis, structure and catalytic activity. $J$. Organomet. Chem. 2009, 694, 2290-2294. (b) Liu, P.; Yan, M.; $\mathrm{He}, \mathrm{R}$. Bis(imino)pyridine palladium(II) complexes as efficient catalysts for the Suzuki-Miyaura reaction in water. Appl. Organomet. Chem. 2010, 24, 131-134. 
(19) Nagai, A.; Nakamura, T.; Nabeshima, T. A twisted macrocyclic hexanuclear palladiumcomplex with internal bulky coordinating ligands. Chem. Commun. 2019, 55, 2421-2424.

(20) (a) Fujita, M.; Yazaki, J.; Ogura, K. Preparation of a macrocyclic polynuclear complex, $\left[(\mathrm{en}) \mathrm{Pd}\left(4,4^{\prime}-\mathrm{bpy}\right)\right]_{4}(\mathrm{NO} 3)_{8}(\mathrm{en}=$ ethylenediamine, bpy = bipyridine), which recognizes an organic molecule in aqueous media. J. Am. Chem. Soc. 1990, 112, 56455647. (b) Fujita, M.; Sasaki, O.; Mitsuhashi, T.; Fujita, T.; Yazaki, J.; Yamaguchi, K.; Ogura, K. On the structure of transition-metallinked molecular squares. Chem. Commun. 1996, 0, 1535-1536.

(21) Stang, P. J.; Cao, D. H.; Saito, S.; Arif, A. M. Self-Assembly of Cationic, Tetranuclear, Pt(II) and Pd(II) Macrocyclic Squares. $\mathrm{X}$-ray Crystal Structure of $\left[\mathrm{Pt}^{2+}(\mathrm{dppp})\left(4,4^{\prime}\right.\right.$-bipyridyl $) 2$ $\left.\mathrm{OSO}_{2} \mathrm{CF}_{3}\right]_{4}$. J. Am. Chem. Soc. 1995, 117, 6273-6283.

(22) Stewart, J. J. P. Optimization of parameters for semiempirical methods V: Modification of NDDO approximations and application to 70 elements. J. Mol. Model. 2007, 13, 1173-1213.

(23) SCIGRESS, Fujitsu Limited, Tokyo, Japan, 2013.

(24) (a) Fujita, N.; Biradha, K.; Fujita, M.; Sakamoto, S.; Yamaguchi, K. A Porphyrin Prism: Structural Switching Triggered by Guest Inclusion. Angew. Chem. Int. Ed. 2001, 40, 1718-1721. (b) Bar, A. K.; Mohapatra, S.; Zangrando, E.; Mukherjee, P. S. A Series of Trifacial $\mathrm{Pd}_{6}$ Molecular Barrels with Porphyrin Walls. Chem.Eur. J. 2012, 18, 9571-9579.

(25) By analogy with the conformers observed in calixarenes (concave oligomeric macrocycles which can also present inversion of separate units), we will name the conformers of the present macrocycles with the same nomenclature. For more details, see: Gutsche, C. D. In Calixarenes: An introduction, 2nd Ed., Monographs in Supramolecular Chemistry; Stoddart, J. F., Ed.; The Royal Society of Chemistry: Cambridge, 2008.

(26) Martí-Centelles, V.; Pandey, M. D.; Burguete, M. I.; Luis, S. V. Macrocyclization Reactions: The Importance of Conformational, Configurational, and Template-Induced Preorganization. Chem. Rev. 2015, 115, 8736-8834.

(27) (a) Leung, K. C.-F.; Aricó, F.; Cantrill, S. J.; Stoddart, J. F. Template-Directed Dynamic Synthesis of Mechanically Interlocked Dendrimers. J. Am. Chem. Soc. 2005, 127, 5808-5810. (b) Rowan, S. J.; Stoddart, J. F. Thermodynamic Synthesis of Rotaxanes by Imine Exchange. Org. Lett. 1999, 1, 1913-1916. (c) Dancey, K. P.; Dell, A.; Henrick, K.; Judd, P. M.; Owston, P. G.; Peters, R.; Tasker, P. A.; Turner, R. W. Dinucleating octaaza macrocyclic ligands from simple imine condensations. J. Am. Chem. Soc. 1981, 103, 4952-4954. (d) Jackson, T. W.; Kojima, M.; Lambrecht, R. M.; Marubayashi, N.; Hiratake, M. Reduction of 6,6,9,9-tetramethylhexahydroimidazo[2,1-d][1,2,5]dithiazepine with borane. Aust. J. Chem. 1994, 47, 2271-2277. (e) Lu, Z. H.; Bhongle, N.; Su, X.; Ribe, S.; Senanayake, C. H. Novel diacid accelerated borane reducing agent for imines. Tetrahedron Lett. 2002, 43, 8617-8620. (f) De Kimpe, N.; Stevens, C. A convenient method for the synthesis of $\beta$-chloroamines by electrophilic reduction of $\alpha$ chloroimines. Tetrahedron 1991, 47, 3407-3416. (g) Nimse, S. B.; Nguyen, V.-T.; Kim, J.; Kim, H.-S., Song, K.-S.; Eoum, W.-Y.; Jung, C.-Y.; Ta, V.-T.; Seelam, S. R.; Kim, T. Water-soluble aminocalix[4]arene receptors with hydrophobic and hydrophilic mouths. Tetrahedron Lett. 2010, 51, 2840-2845. (h) Kerneghan, P. A.; Halperin, S. D.; Bryce, D. L.; Maly, K. E. Postsynthetic modification of an imine-based microporous organic network. Can. J. Chem. 2011, 89, 577-582. (i) Das, U. K.; Daifuku, S. L.; Iannuzzi, T. E.; Gorelsky, S. I.; Korobkov, I.; Gabidullin, B.; Neidig, M. L.; Baker; R. T. Iron(II) Complexes of a Hemilabile SNS Amido Ligand: Synthesis, Characterization, and Reactivity. Inorg. Chem. 2017, 56, 13766-13776. (j) Akita, S.; Nakano, R.; Ito, S.; Nozaki, K. Synthesis and Reactivity of Methylpalladium Complexes Bearing a Partially Saturated IzQO Ligand. Organometallics 2018, 37, 2286-2296.
(28) (a) Hunter, C. A.; Anderson, H. L. What is Cooperativity? Angew. Chem. Int. Ed. 2009, 48, 7488-7499. (b) von Krbek, L. K. S.; Schalley, C. A.; Thordarson, P. Assessing cooperativity in supramolecular systems. Chem. Soc. Rev. 2017, 46, 2622-2637.

(29) Cavity volume calculated with PLATON software: Probe radius $=1.2 \AA$; Grid step $=0.1 \AA$; Atomic radii: $\mathrm{C}=1.70 \AA \AA \mathrm{H}=1.20$ $\AA ̊ \mathrm{~N}=1.55 \AA$ 年 $\mathrm{O}=1.52 \AA$; $\mathrm{Pd}=1.63 \AA$ Å. See: Spek, A. L. Structure validation in chemical crystallography. Acta Cryst. 2009, D65, 145-155.

(30) Tranchemontagne, D. J.; Ni, Z.; O'Keeffe, M.; Yaghi O. M. Reticular Chemistry of Metal-Organic Polyhedra. Angew. Chem. Int. Ed. 2008, 47, 5136-5147.

(31) A tetrafold connector (tetrakis(4-aminophenyl)porphyrin) was also considered for potential cage formation but geometrical features of this building block prevented the formation of a discrete structure (see SI and Figures S81-S82 for details).

(32) (a) Bilbeisi, R. A.; Clegg, J. K.; Elgrishi, N.; de Hatten, X.; Devillard, M.; Breiner, B.; Mal, P.; Nitschke, J. R. Subcomponent Self-Assembly and Guest-Binding Properties of Face-Capped $\mathrm{Fe}_{4} \mathrm{~L}_{4}{ }^{8+}$ Capsules. J. Am. Chem. Soc. 2012, 134, 5110-5119. (b) Rizzuto, R. J.; Wu, W.-Y.; Ronson, T. K.; Nitschke, J. R. Peripheral Templation Generates an $\mathrm{M}_{6}{ }_{6} \mathrm{~L}_{4}$ Guest-Binding Capsule. Angew. Chem. Int. Ed. 2016, 55, 7958-7962. (c) Rizzuto, R. J.; Kieffer, M.; Nitschke, J. R. Quantified structural speciation in self-sorted $\mathrm{Co}_{6}{ }_{6} \mathrm{~L}_{4}$ cage systems. Chem. Sci. 2018, 9, 1925-1930.

(33) (a) Fujita, M.; Oguro, D.; Miyazawa, M.; Oka, H.; Yamaguchi, K.; Ogura, K. Self-assembly of ten molecules into nanometresized organic host frameworks. Nature 1995, 378, 469-471. (b) Yoshizawa, M.; Tamura, M.; Fujita, M. Diels-Alder in Aqueous Molecular Hosts: Unusual Regioselectivity and Efficient Catalysis. Science 2006, 312, 251-254. (c) Yoshizawa, M.; Kusukawa, T.; Kawano, M.; Ohhara, T.; Tanaka, I.; Kurihara, K.; Niimura, N.;Fujita M. Endohedral Clusterization of Ten Water Molecules into a "Molecular Ice" within the Hydrophobic Pocket of a Self-Assembled Cage. J. Am. Chem. Soc. 2005, 127, 2798-2799. (d) Furusawa, T.; Kawano, M.; Fujita, M. The Confined Cavity of a Coordination Cage Suppresses the Photocleavage of $\alpha$-Diketones To Give $\mathrm{Cy}$ clization Products through Kinetically Unfavorable Pathways. Angew. Chem. Int. Ed. 2007, 46, 5717-5719. (e) Takezawa, H.; Murase, T.; Resnati, G.; Metrangolo, P.; Fujita, M. Recognition of Polyfluorinated Compounds Through Self-Aggregation in a Cavity. J. Am. Chem. Soc. 2014, 136, 1786-1788.

(34) (a) Belowich, M. E.; Stoddart, J. F. Dynamic imine chemistry. Chem. Soc. Rev. 2012, 41, 2003-2024. (b) Vardhan, H.; Mehta, A.; Nath, I.; Verpoort, F. Dynamic imine chemistry in metal-organic polyhedra. RSC Adv. 2015, 5, 67011-67030. (c) Kovaříček, P.; Jean-Marie Lehn, J.-M. Merging Constitutional and Motional Covalent Dynamics in Reversible Imine Formation and Exchange Processes. J. Am. Chem. Soc. 2012, 134, 9446-9455.

(35) (a) Hristova, Y. R.; Smulders, M. M. J.; Clegg, J. K.; Breiner, B.; Nitschke, J. R. Selective anion binding by a "Chameleon" capsule with a dynamically reconfigurable exterior. Chem. Sci. 2011, 2, 638-641. (b) Wood, C. S.; Ronson, T. K.; Belenguer, A. M.; Holstein, J. J.; Nitschke, J. R. Two-stage directed self-assembly of a cyclic [3] catenane. Nat. Chem. 2015, 7, 354-358. (c) Roberts, D. A.; Pilgrim, B. S.; Sirvinskaite, G.; Ronson, T. K.; Nitschke, J. R. Covalent Post-assembly Modification Triggers Multiple Structural Transformations of a Tetrazine-Edged $\mathrm{Fe}_{4} \mathrm{~L}_{6}$ Tetrahedron. J. Am. Chem. Soc. 2018, 140, 9616-9623.

(36) Hansch, C.; Leo, A.; Taft, R. W. A survey of Hammett substituent constants and resonance and field parameters. Chem. Rev. 1991, 91, 165-195.

(37) (a) Hogg, L.; Leigh, D. A.; Lusby, P. J.; Morelli, A.; Parsons, S.; Wong, J. K. Y. A Simple General Ligand System for Assembling Octahedral Metal-Rotaxane Complexes. Angew. Chem. Int. Ed. 2004, 43, 1218-1221. 
(38) Mastalerz, M.; Bhat, A.; Elbert, S.; Rominger, F.; Zhang W.S.; Schröder, R.; Dieckmann, M.; Transformation of a [4+6] Salicylbisimine Cage to Chemically Robust Amide Cages. Angew. Chem. Int. Ed. 2019, 58, 8819-8823. 
Graphic entry for the Table of Contents (TOC)

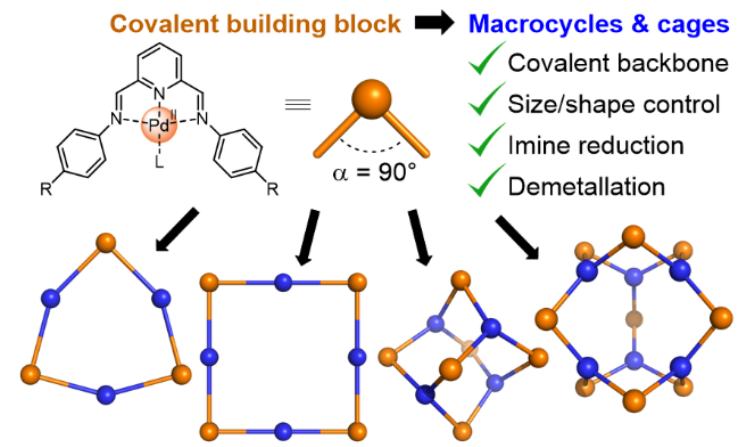

